\title{
Comparative Study of Corrosion Sensitivity of Selected Ferrous Metals in Crude Oil
}

\author{
Ogundare, O., Momoh, I.M., Akinribide, O.J., *Adetunji, A.R., ${ }^{1}$ Borode, J.O., \\ ${ }^{+}$Olusunle, S.O.O. and ${ }^{+}$Adewoye, O.O. \\ Engineering Materials Development Institute, Akure, Nigeria. \\ *Prototype Engineering Development Institute, Ilesa, Nigeria. \\ ${ }^{1}$ Department of Metallurgical and Materials Engineering, Federal University of Technology, \\ Akure, Nigeria. \\ ${ }^{+}$National Agency for Science and Engineering Infrastructure, Abuja, Nigeria.
}

Corresponding Author: suppiedee@yahoo.com

\begin{abstract}
Corrosion characteristic of selected ferrous metal samples (plain and alloyed ductile iron, low carbon steel and austenitic stainless steel) in crude oil was investigated using weight loss method. The microstructures of the coupons were taken before and after corrosion test. It was observed that all the materials experience gain in weight within the first 10 days in the medium. This weight gain is attributed to the formation of hard and passive phases which acted as strong protective barriers to corrosion. It was also observed that the rate of corrosion decreased with increase in the number of days of exposure for all the coupons, this may be probably due to the deposition of corrosion products that tend to shield the corroding surface from further corrosion attack, there by depressing the rate of corrosion. This result shows that despite initial low corrosion resistance of plain ductile iron, it can still be considered, alongside other materials, for application in pipelines and storage facilities for crude oil.
\end{abstract}

Keywords: Corrosion, agitation, ductile iron, Austenitic Stainless Steel, Mild steel and crude oil.

\section{INTRODUCTION}

Ferrous materials which include steels and cast irons of various compositions have all demonstrated their usefulness in structural (e.g residential buildings, bridges etc) and domestic 
applications. Its relevance in pipelines cannot be over-emphasized considering its vast use in the oil sector. Ferrous materials have gain prevalence over many other materials in the aforementioned applications. This unique noticeable prevalence has been attributed, among others, to spring from its response to harsh corrosive conditions/environments along with appreciable mechanical properties [1].

Ductile iron or nodular cast iron or spheroid-graphite (SG) cast iron contains nodules of graphite embedded in a matrix of ferrite or pearlite or both, the graphite separates out as nodules from iron during solidification because of the additives like magnesium (Mg) and Silicon ( $\mathrm{Si}$ ) introduced into the molten iron before casting. These nodules act as crack arresters thereby improving the mechanical properties of ductile iron. Its corrosion resistance has been attributed to the formation of a thin passive barrier film of hydrated oxides of silicon on the metal surface. The film develops with time due to the dissolution of iron from the metal matrix leaving behind silicon which hydrates due to the presence of moisture. The passive hydrated silicon film is thought to bridge over and form an impervious barrier layer on a fine grained high silicon cast iron with spheroidal graphite areas much more readily than on a high silicon cast iron with coarse graphite flakes [2].

Corrosion, which has been conveniently classified according to the manner in which it manifest itself [3] is regularly encountered in the chemical, petrochemical, oil, and food processing industries; in the air, sea, rail, and road transportation; in conventional and nuclear power generation station; in buildings and construction industries; in agriculture and in numerous domestic applications.

Passivity is the loss of chemical reactivity, under particular environmental conditions, by some active metals and alloys. It is the result of the formation of a highly protected but thin and sometimes invisible film on the surface of a metal or an alloy that makes its soluble potential nobler. This, however, does not take into consideration the position of the metal in the electrochemical series. This is, among others, the function of most corrosion resistance alloying elements (e.g chromium, nickel, vanadium etc) in metals [4].

Since metals and alloys form the essential basis for modern technological civilization, the harmful repercussions are extremely wide spread and diverse; the problem of metallic corrosion is one of significant proportions; in economic terms, it has been estimated that approximately 5\% of an industrialized nation's income is spent on corrosion prevention and the maintenance or replacement of products lost or contaminated as a result of corrosion reactions. Therefore the need arise to examine their corrosion behavior so as to reduce or even stop their corrosion [3]. The stress corrosion behavior of low and medium carbon steels in agro- fluids was evaluated and discovered that low carbon steel in both media exhibit high corrosion resistance due to the low amount of carbon content [5]. 
Nigeria, as an oil producing nation, needs to intensify research in the area of ferrous metal applications. In order to assess and evaluate the life-span of the materials employed in such transportation and storage, this research has embarked on the comparative study of various selected materials in mildly agitated crude oil.

\section{MATERIALS AND METHOD}

\subsection{Materials and Equipment}

The materials used in this experiment include mild steel, austenitic stainless steel; plain ductile iron and alloyed ductile irons were produced from EMR 100 rotary furnace at Engineering Materials Development Institute Akure and crude oil obtained from the oil field. Equipment used for the experiment are bench vice, Digital analytical balance, Atomic Absorption Spectrophotometer (AAS), Instron tensile testing machine, microhardness tester, Buehler mounting press, grinding and polishing machines. The composition of the crude oil is shown in table 1 below.

Table 1: Compositional Analysis for the Crude oil

\begin{tabular}{|l|l|l|}
\hline CONTENT & $\begin{array}{l}\text { CONCENTRATION } \\
\text { (ppm) }\end{array}$ & AMOUNT (\%) \\
\hline Iron & 0.3105 & 0.000776 \\
\hline Copper & 0.2331 & 0.000583 \\
\hline Nickel & 0.05678 & 0.00142 \\
\hline Sulphur & 1863.85 & 0.1863 \\
\hline $\begin{array}{l}\text { Carbon (in } \\
\text { hydrocarbon) }\end{array}$ & 1340 & 46.8 \\
\hline
\end{tabular}

Table 2: Chemical composition of the selected ferrous metals

\begin{tabular}{|l|l|l|l|l|l|l|l|l|l|l|l|l|l|l|}
\hline $\begin{array}{l}\text { Composition } \\
\text { (\%) }\end{array}$ & $\mathbf{C}$ & $\mathbf{S i}$ & $\mathbf{P}$ & $\mathbf{M n}$ & $\mathbf{S}$ & $\mathbf{M o}$ & $\mathbf{M g}$ & $\mathbf{C o}$ & $\mathbf{A l}$ & $\mathbf{C u}$ & $\mathbf{N i}$ & $\mathbf{C r}$ & $\mathbf{N b}$ & $\mathbf{F e}$ \\
\hline Plain D.I & 3.60 & 2.00 & 0.007 & 0.300 & 0.010 & 0.014 & 0.05 & - & - & - & - & - & - & Bal. \\
\hline $\mathbf{N i}$ - D.I & 3.72 & 1.98 & 0.005 & 0.220 & 0.011 & 0.012 & 0.07 & - & - & - & 0.90 & - & - & Bal. \\
\hline Cr -D.I & 3.97 & 2.01 & 0.008 & 0.233 & 0.010 & 0.016 & 0.10 & - & - & - & - & 0.8 & - & Bal. \\
\hline Ni/Cr - D.I & 3.51 & 2.12 & 0.004 & 0.150 & 0.008 & 0.020 & 0.07 & - & - & - & 0.36 & 0.90 & - & Bal. \\
\hline Mild Steel & 0.117 & 0.033 & 0.0258 & 0.011 & 0.014 & 0.014 & - & 0.005 & 0.59 & 0.055 & 0.19 & - & - & Bal. \\
\hline ASS & 0.08 & 0.75 & 0.045 & 2.00 & 0.030 & 2.50 & - & - & - & - & 8.0 & 18.0 & 0.1 & Bal. \\
\hline
\end{tabular}




\subsection{Method}

Sample preparation: The as-cast and as-received samples were machined to a specific preferred corrosion configuration. It was further ground and polished after which the hardness values were determined with the aid of a micro-hardness tester.

Microstructural Examination: Metallographic samples were cut from the coupons before immersion. The cut samples were then mounted in Bakelite, impregnated emery paper (60-2400 grits) sizes were used to grind the samples, and then polished, etched and the photomicrographs were taken after 56 days of immersion in crude oil for comparison.

Corrosion Test: After machining, the coupons were cleaned, weighed and stored in a dessicator before suspending it in crude oil with the aid of threads at room temperature of $27^{\circ} \mathrm{C}$. Each test coupon was exposed for a total period of 56 days with seven weight measurements taken at an interval of 7 days. The average corrosion rates of the coupons, measured in $\mathrm{mg} / \mathrm{mm}^{2} / \mathrm{yr}$ were determined using the following established relation $[6,7,8,9,10]$.

Weight Loss/corrosion Rate: The weight losses of the coupons were determined by finding the difference between the original weights of the coupons and the new weights after each withdrawal.

\section{RESULTS AND DISCUSSION}

\subsection{Results}

Table 3: Vicker's hardness values of the selected ferrous metals

\begin{tabular}{|l|l|}
\hline Materials & Hardness values (HV) \\
\hline Ni-DI & 278.2 \\
\hline Cr-DI & 239.7 \\
\hline Mild steel & 117.9 \\
\hline ASS & 203.5 \\
\hline Ni-Cr-DI & 300.5 \\
\hline Plain DI & 279.2 \\
\hline
\end{tabular}




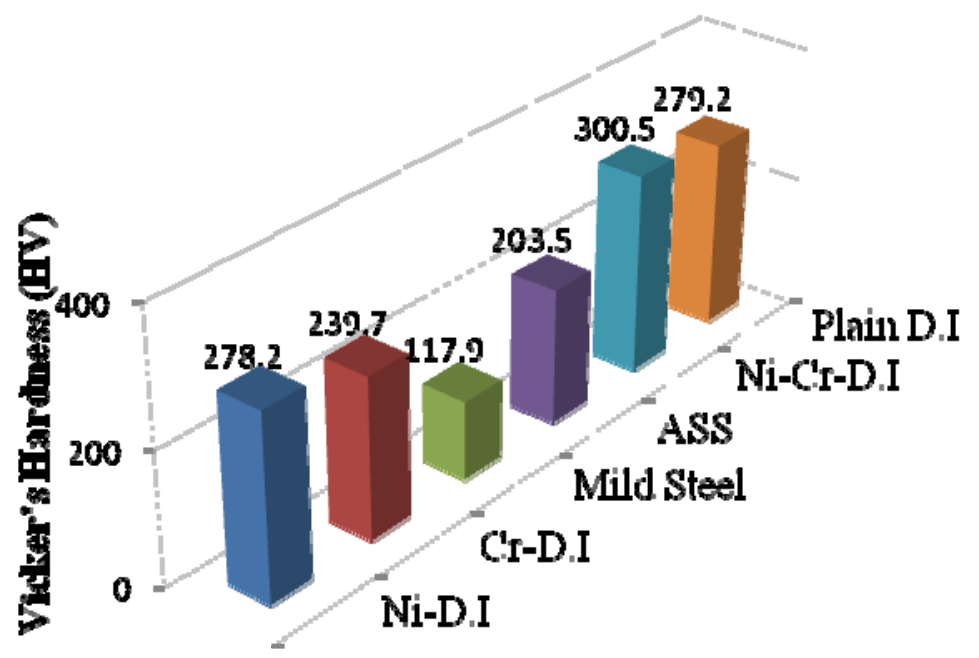

Fig. 1: graph showing the hardness properties of some selected ferrous materials.

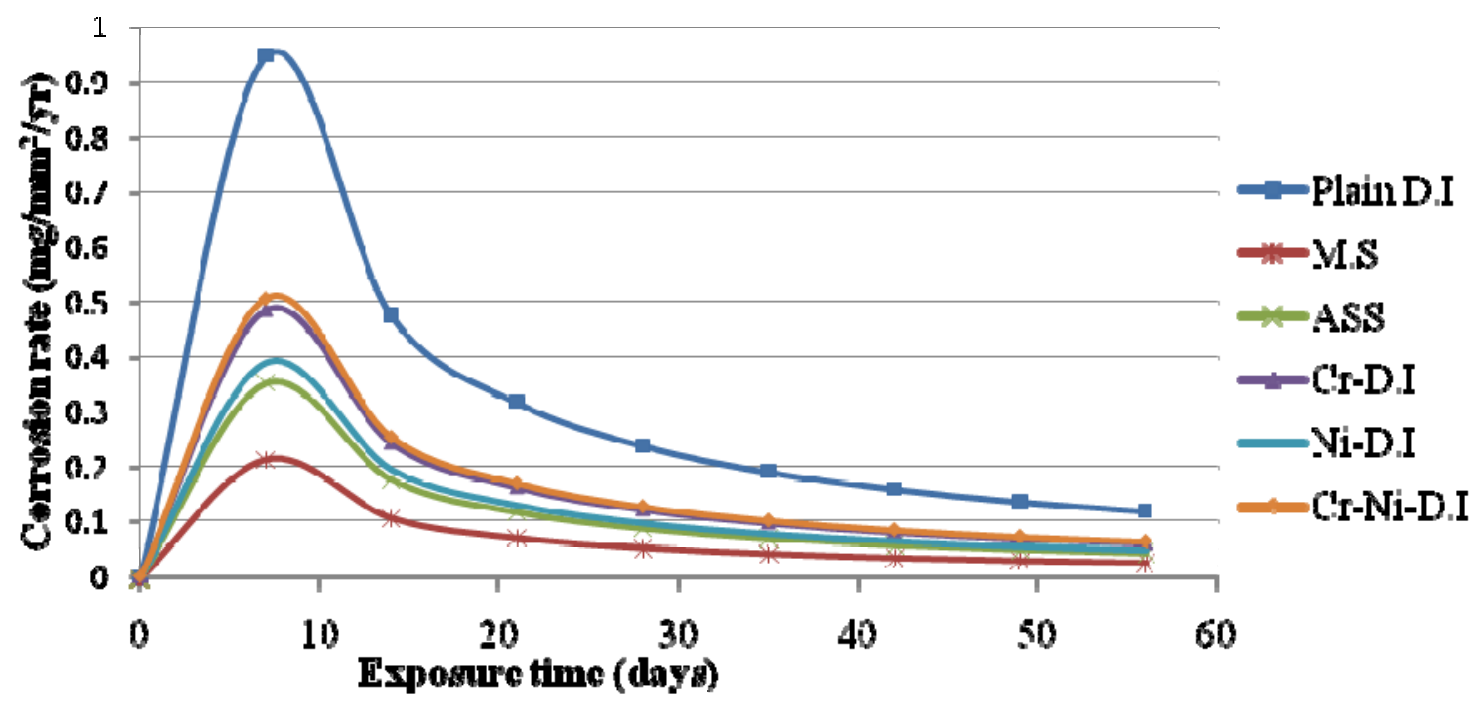

Fig. 2: combined graph showing the corrosion behavior of ductile irons of various compositions, Mild steel and Austenitic Stainless Steel with respect to each other subjected to corrosion in crude oil. 

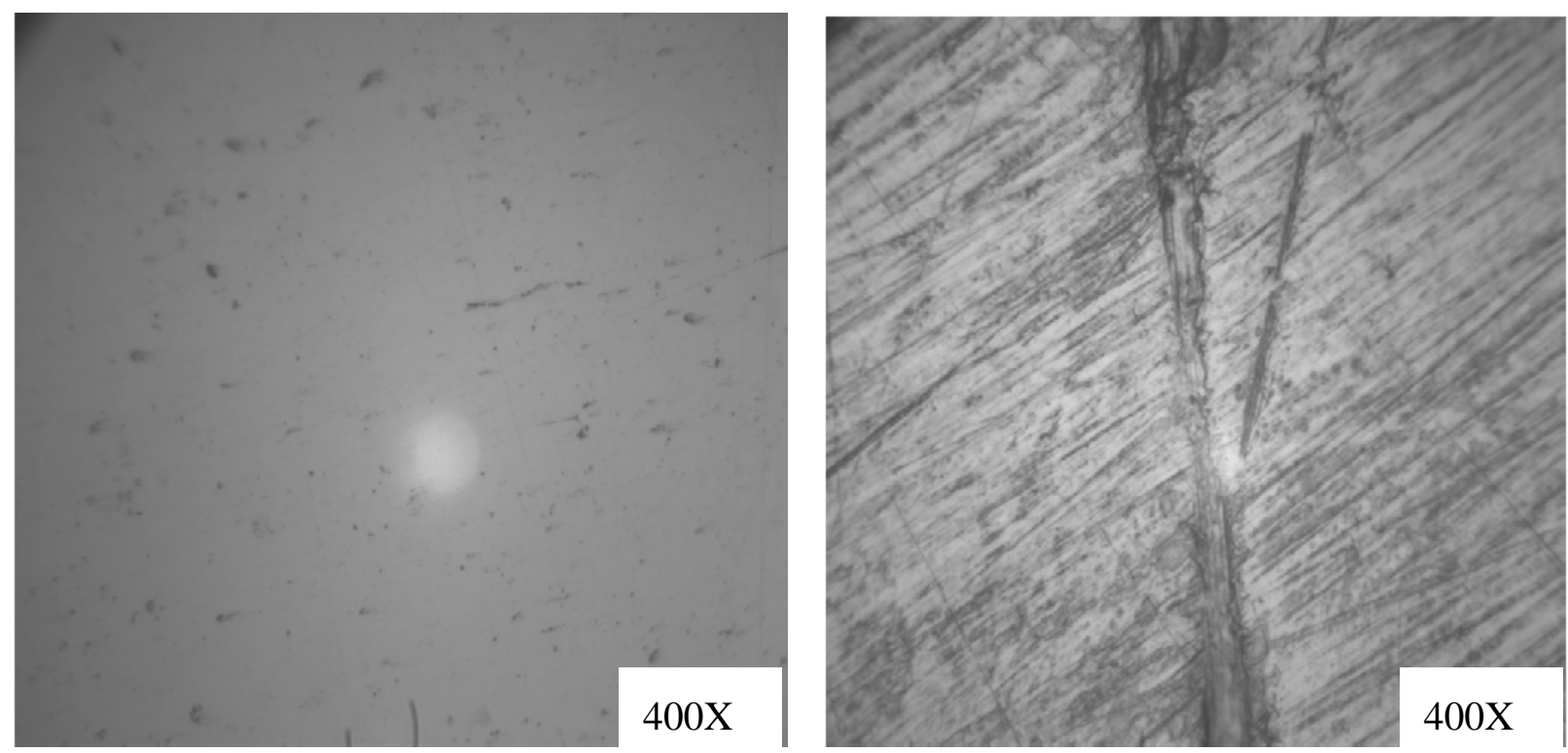

Fig. 3a: Microstructure of Austenitic Stainless Steel (a) before corrosion (LHS) and (b) after 56 davs in crude oil (RHS).
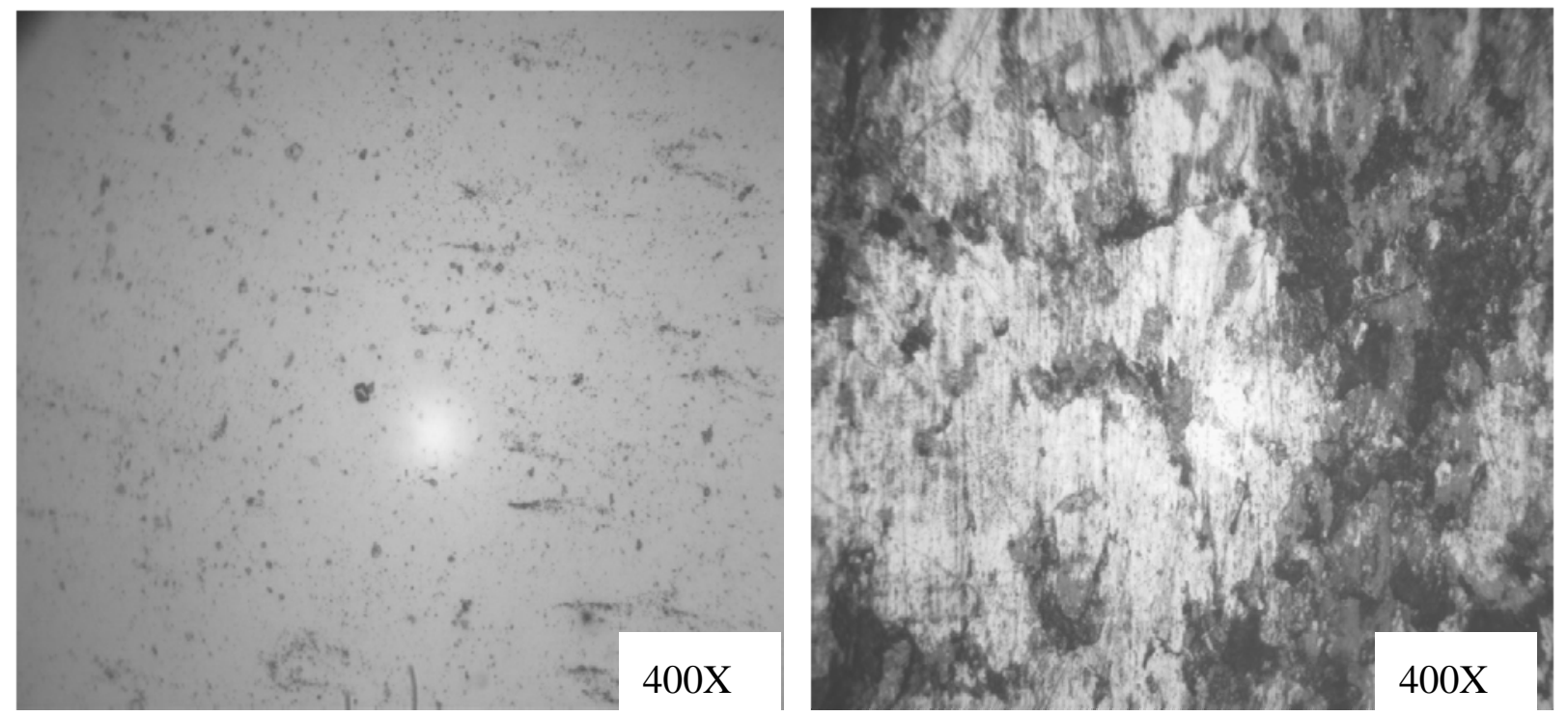

Fig. 3b: Microstructure of Mild Steel (a) before corrosion (LHS) and (b) after 56 days in crude oil (RHS). 

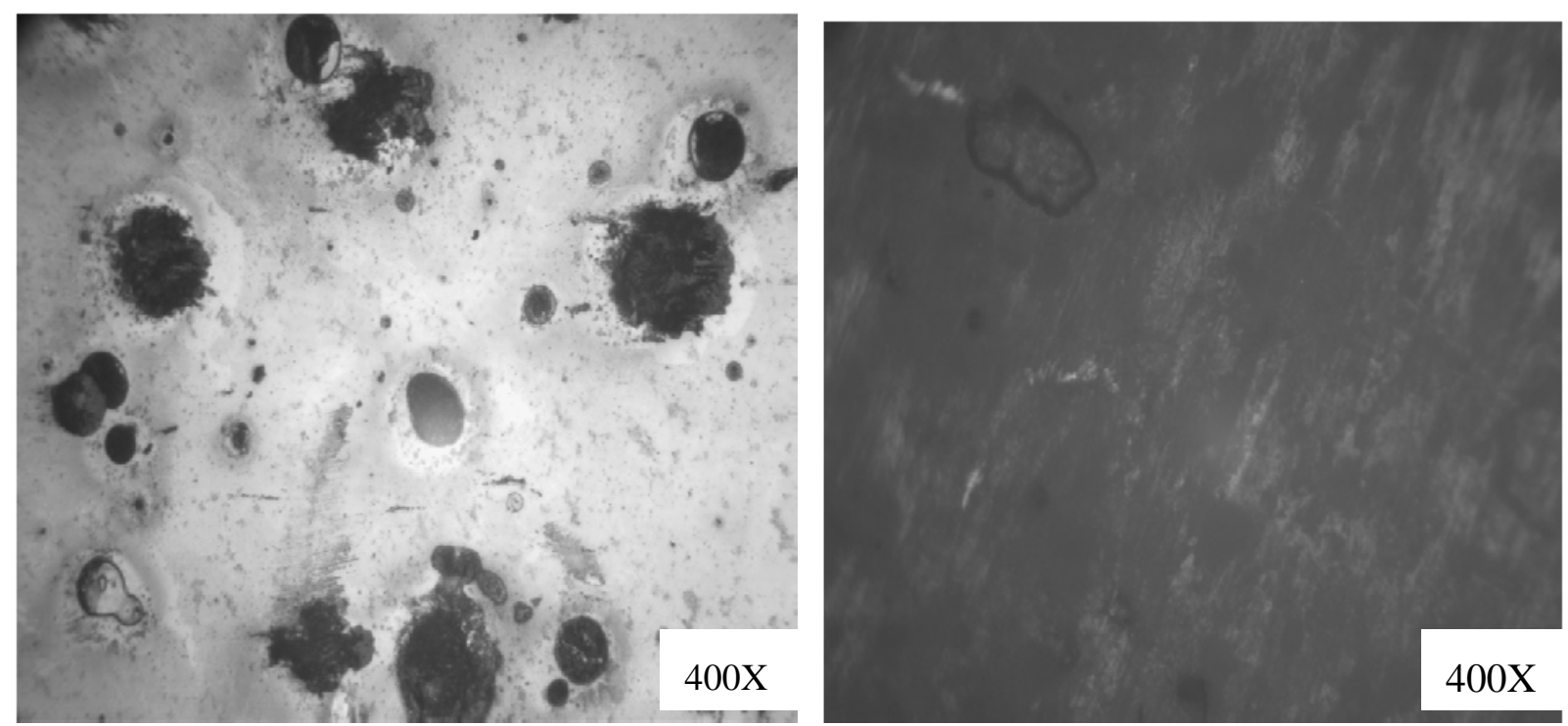

Fig. 3c: Microstructure of Chromium Alloyed Ductile Iron (a) before corrosion (LHS) and (b) after 56 days in crude oil (RHS).
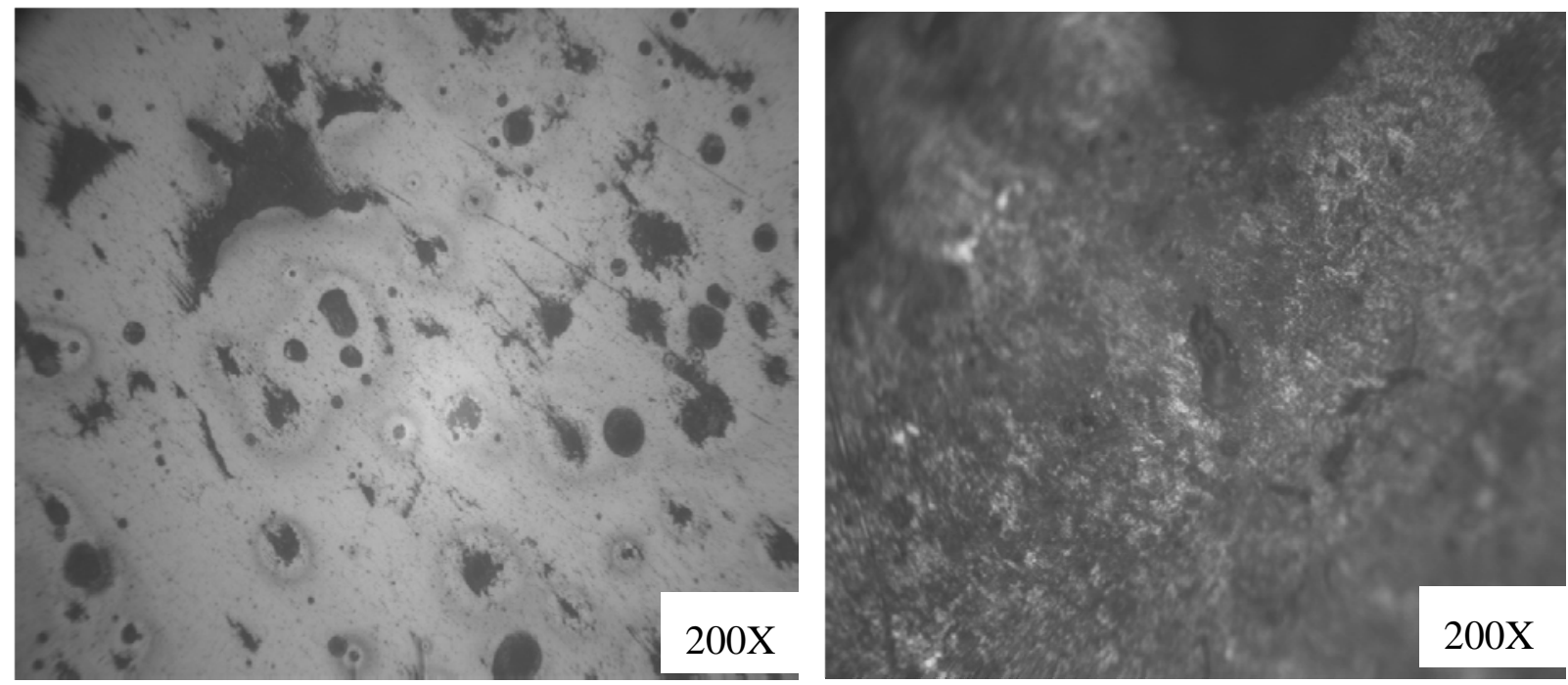

Fig.3d: Microstructure of Nickel Alloyed Ductile Iron (a) before corrosion (LHS) and (b) after 56 days in crude oil (RHS). 

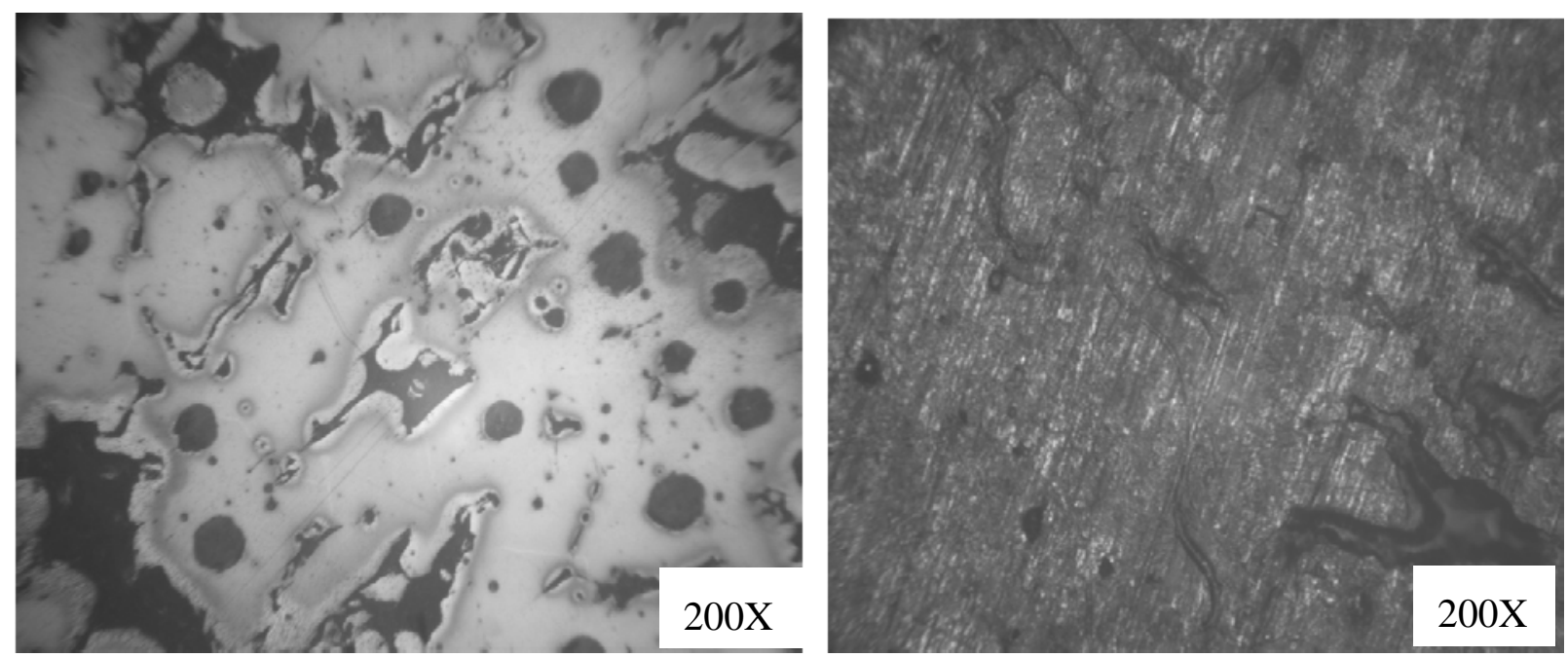

Fig.3e: Microstructure of Nickel - Chromium Alloyed Ductile Iron (a) before corrosion (LHS) and (b) after 56 days in crude oil (RHS).
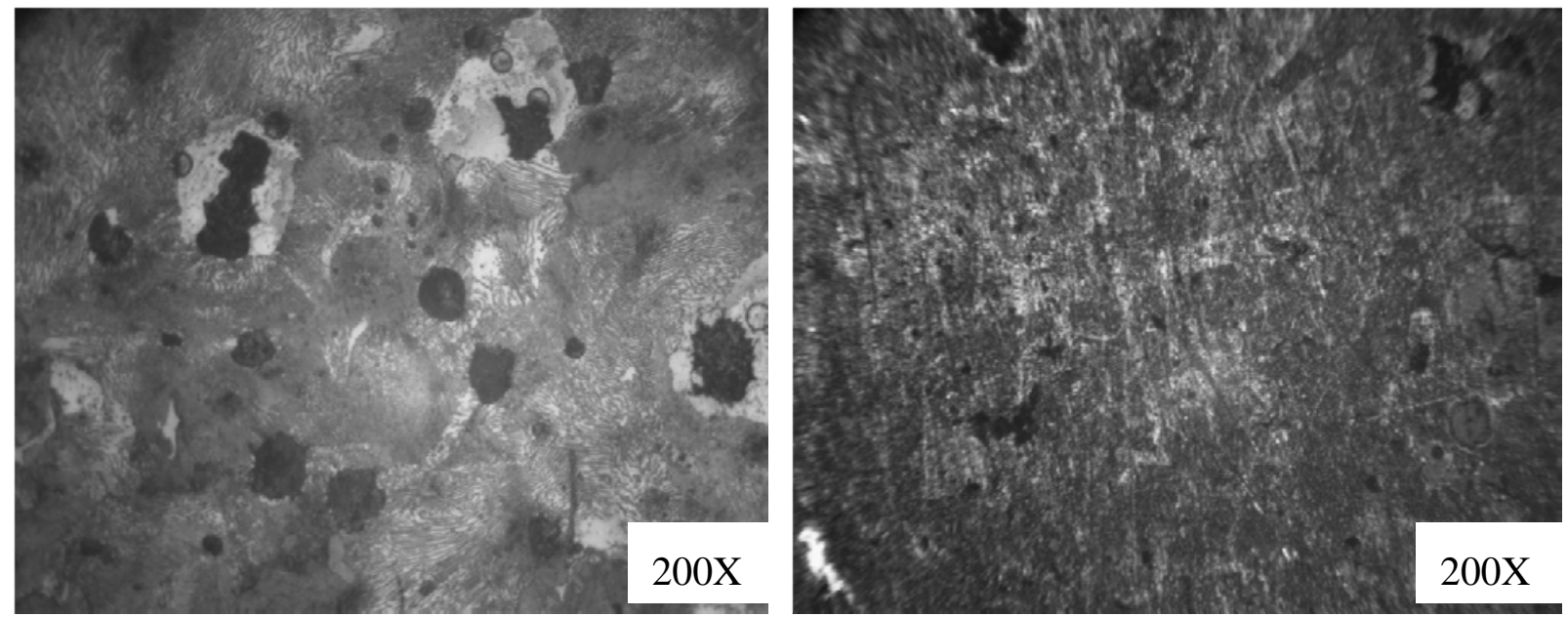

Fig.3f: Microstructure of Plain Ductile Iron (a) before corrosion (LHS) and (b) after 56 days in crude oil (RHS).

\subsection{Discussion}

Figure 1 shows the hardness values of the selected ferrous materials. The materials were observed to possess a relatively high hardness property (see figure 1) indicating that all of them have adequate strength to withstand the stress posed by floating crude oil.

Figure 2 shows the corrosion behavior of the materials and interestingly shows that the majority has high corrosion resistance property in crude oil. The corrosion deposit observed in the microstructure was in a regular orientation (fig. 3a) which could be inferred from the 
directionality of the slip plane with respect to the manufacturing process. All the immersed samples experience an increase in corrosion rate between first 8-10 days. This is attributed to the formation of hard and passive phases which acted as strong protective barriers to corrosion. However, after the tenth day measurement, It was also observed that the rate of corrosion gradually decreases with increase in the number of days of exposure time for all the coupons, this may be probably due to the deposition of corrosion products that tend to shield the corroding surface from further corrosion attack, there by depressing the rate of corrosion. This observation is similar to the findings of literature review [1]. Surprisingly, mild steel was observed to have the lowest corrosion rate because it is the least susceptible to crude oil attack. This observation supports the report of Badmus et al. who worked extensively on corrosion in petroleum pipelines [5].

The presence of chromium and nickel in the alloyed ductile iron and silicon in mild steel forced the reactive ions (anodic potential) to become passive on reacting with the sulphide or oxides in the crude oil (to form e.g silicon oxide) and hence, stops further attack. This phenomenon is indicated by the predominant dark phase on their respective micrographs (fig. 3a, c, d and e). The breaking -up and the reformation of the thin film (especially in nickel alloyed ductile iron) may be due to environmental alterations like concentration, temperature, velocity of agitation.

However, plain ductile iron shows a noticeably high corrosion rate due to vicious attack on the surface resulting in pitting corrosion as shown in the micrograph (fig. 4f), .Thus; this would be the least recommended metal for application in crude oil from corrosion viewpoint.

\section{CONCLUSION}

1. The rate of corrosion decreased with increase in the number of days of exposure for all the coupons

2. Plain ductile iron shows the lowest corrosion resistance in mildly agitated crude oil.

\section{REFERENCES}

[1]. Raymond A. Higgins. 2004. Engineering Metallurgy Applied Physical Metallurgy; Vinod Vasishtha for Viva Books Private Limited; New Delhi.

[2]. Aigbodion, V.S., Mohammed, O.Y., Yakubu, S.I. and Agunsoye, J.O. 2007. "Corrosion Characteristics of Vanadium Alloyed Ductile Cast Iron in Nitric Acid”. J. Applied Sciences Research, Vol. 4, No 10, pp. 1267-1271.

[3]. William D. Calister Jr. 2003. Materials Science and Engineering: An Introduction. John Wiley \& Sons, Inc. New York.

[4]. Khana O.P. 2009. Materials Science and Metallurgy; Dhanpet Rai and Sons Publication, New Delhi. 
[5]. Afolabi A.S. 2007. "Corrosion and Stress Corrosion Behaviors of Low and Medium Carbon Steels in Agro-Fluid Media”, Leonardo Electronic J. Practices and Technologies, Vol. 10, pp. 55-66.

[6]. Badmos, A.Y, Ajimotakan, H.A and Emmanuel, E.O. 2009. "Corrosion in Petroleum Pipelines”. New York Science J. Vol. 2, No 5, pp. 36 - 40.

[7]. Lawal, A.I. 2005. "Corrosion of Carbon Steel in Natural and Packed Orange Juice”. B. Eng. Thesis, Department of Mechanical Engineering, University of Ilorin, Nigeria

[8]. Osarolube, E., Owate, I.O. and Oforka, N.C. 2004. "The Influence of Acidity Concentrations on Corrosion of Copper and Zinc”. J. Corrosion Science and Technology, Vol.1, No 1, pp. 66-69.

[9]. Ovri, J. E. and Ofeke, T.B. 1998. “The Corrosion of Mild Steel in Marine Environment”. J. Science Engineering Technology, Vol. 5, No 2, pp. 1117-1129.

[10]. Gregory, O. W. 2004. "Corrosion Resistance of Copper and Brass in Various Media”. J. Corrosion Science and Technology, Vol. 1, No 1, pp. 58-60. 